\title{
GEOGRAPHIC VARIATION IN THE ROSY THRUSH-TANAGER (RHODINOCICHLA ROSEA) COMPLEX OF MESOAMERICA (AVES: PASSERIFORMES)
}

\author{
A. Townsend Peterson ${ }^{1}$, Nathan H. Rice ${ }^{1,2}$, and Adolfo G. Navarro-Sigüenza ${ }^{3}$
}

Biota Neotropica v4 (n2)- http://www.biotaneotropica.org.br/v4n2/pt/abstract?short-communication+BN02304022004

\author{
Date Received: 04/16/2004 \\ Revised: 06/24/2004 \\ Accepted: 07/01/2004
}

\begin{abstract}
${ }^{1}$ Department of Ecology and Evolutionary Biology, Natural History Museum, The University of Kansas, Lawrence, Kansas 66045 USA.

${ }^{2}$ Current Address: Ornithology Department, Academy of Natural Sciences, Philadelphia, Pennsylvania 19103 USA

${ }^{3}$ Museo de Zoología, Facultad de Ciencias, UNAM, Apartado Postal 70-399, México, D. F. 04510 México.
\end{abstract}

\begin{abstract}
Patterns of differentiation and geographic variation among populations of the Rhodinocichla complex are described. We document the existence of a heretofore unreported population in the vicinity of Acapulco, Guerrero, Mexico. The species occurs in 4-6 allopatric populations, each of which has unique characters that make it diagnosable. We recommend that the complex be considered a single biological species, but at least five phylogenetic species.
\end{abstract}

Key words:

\section{Resumen}

Se describen los patrones de diferenciación y variación geográfica entre poblaciones del complejo de Rhodinocichla. Se documenta la existencia de una población antes no conocida en los alrededores de Acapulco, Guerrero, México. La especie se encuentra dividida en 4-6 poblaciones alopátricas, cada una de las cuales tiene caracteres únicos que permiten diagnosticar a la población. Se recomienda que el compejo sea considerado como una sola especie biológica o como por lo menos cinco especies filogenéticas.

\section{Palavras-chave:}

http://www.biotaneotropica.org.br 


\section{Introduction}

One of the most enigmatic of Mesoamerican birds is the ground-dwelling Rosy Thrush-Tanager (Rhodinocichla rosea). Originally described as a member of the Furnariidae (Lesson 1832), this aberrant monotypic genus has been placed variably with the Troglodytidae, Mimidae (Skutch 1962), Thraupidae (Eisenmann 1962), and Parulinae(Webster 1988). Clearly, Rhodinocichla does not fit easily into any of the presently recognized families of birds, although a recent molecular study argued strongly for its placement with the Emberizidae, possibly in the Thraupinae (Seutin and Bermingham 1997).

Equally interesting, and even less-studied regarding Rhodinocichla, however, are the details of their geographic distribution and morphological variation. The species' distribution is patchy, constituting a series of disjunct populations (Figure 1): the form schistacea of Sinaloa to Colima in western Mexico, a previously unreported population in Guerrero (in the surrondings of the Laguna de Tres Palos, a coastal lagoon very close to Acapulco), eximia of Pacificslope Costa Rica and Panama, beebei and harterti of northeastern Colombia and northwestern Venezuela, and nominate rosea of northern Venezuela. Each population may prove genetically isolated from all others. Although geographic differences among populations are striking, with variation in size, shape, and coloration, geographic variation in the genus has not been treated apart from the original descriptions of subspecies. The purpose of the present contribution is therefore to summarize variation of characters of coloration and morphology among Rhodinocichla populations.

\section{Methods}

To permit detailed comparisons, we assembled 171 study skins of Rhodinocichla from the following museums for study: Academy of Natural Sciences of Philadelphia, Field Museum of Natural History, Carnegie Museum of Natural History, Louisiana State University Museum of Natural Science, Southwestern College, U. S. National Museum of Natural History, Occidental College Moore Laboratory of Zoology, University of California Museum of Vertebrate Zoology, University of Kansas Natural History Museum, Delaware Museum of Natural History, and the University of Michigan Museum of Zoology.

For each adult individual, we measured bill length, depth, and width (all in the plane of the anterior edge of the nostril), tarsus length, wing chord, and tail length. Given variable bill coloration, we also recorded the percent yellow (as opposed to blackish gray) for the maxilla and mandible of each individual, using methods from Peterson (1991a, 1991b). Prior tests for repeatability of morphological measurements indicated that more than $90 \%$ of the variation in our measurements reflect differences in the specimens, and not measurement error (Navarro-Sigüenza, et al. 1992). Coloration differences were determined by direct comparison of series under sunlit conditions and we selectively eliminated from analysis any specimen showing obvious signs of unnatural plumage coloration (i.e., foxing). Differences among sexes in measurements were tested using nonparametric Mann-Whitney $U$-tests on the largest single-population sample available. Normality of distributions was assessed using measures of skewness and kurtosis, and by visual inspection of frequency histograms. Geographic variation in soft-part and plumage color within and among populations was tested using Kruskal-Wallis tests. Finally, patterns of structure for the morphological measurements and color variation were analyzed using cluster analysis.

\section{Results}

A previously unknown population of Rhodinocichla from the vicinity of Acapulco and nearby Laguna de Tres Palos, Guerrero, Mexico (ca. $16.8^{\circ} \mathrm{N} 99.7^{\circ} \mathrm{W}$ ), was represented by 19 specimens (15 Delaware Museum of Natural History, 3 Occidental College Moore Laboratory of Zoology, 1 U. S. National Museum of Natural History). This population may be allopatric from the populations of the west because no specimen is known between Río Nexpa, Michoacán, and Tecpan de Galeana, Guerrero, west of Acapulco. Many of these previously undocumented specimens were collected by Sóstenes Romero, a local collector from Acahuizotla, who was employed by Allan R. Phillips for many years. Further studies along the coastal plain of Michoacán and western Guerrero will be necessary to determine the degree of geographic continuity of these populations. Because of its possible allopatry, this population was maintained separate in our analyses.

Eliminating immatures and imprecisely labeled individuals, 112 adult specimens were measured for statistical analysis. Because sample sizes were relatively low, populations were grouped into four units for statistical analysis: western Mexico (12 males, 14 females, schistacea), Acapulco (11 males, 4 females), Costa Rica and Panama (24 males, 19 females, eximia), Colombia and Venezuela (combining 7 males, 3 females, harterti; 12 males, 6 females, rosea; 1 male, beebei). (South American populations are considered in more detail below with regard to their plumage coloration.)

Based on analyses of the largest sample available (eximia), measurements were far from normally distributed, such that no transformation would normalize them. Therefore, nonparametric statistics were used throughout to assess significance of population differences, and multivariate approaches were avoided. Males were significantly larger than females in three of six measurements (Mann-Whitney $U$-tests, $P<0.05$ ), so sexes were analyzed separately.

Significant differences among populations were detected in each morphological measurement (Kruskal-Wallis 


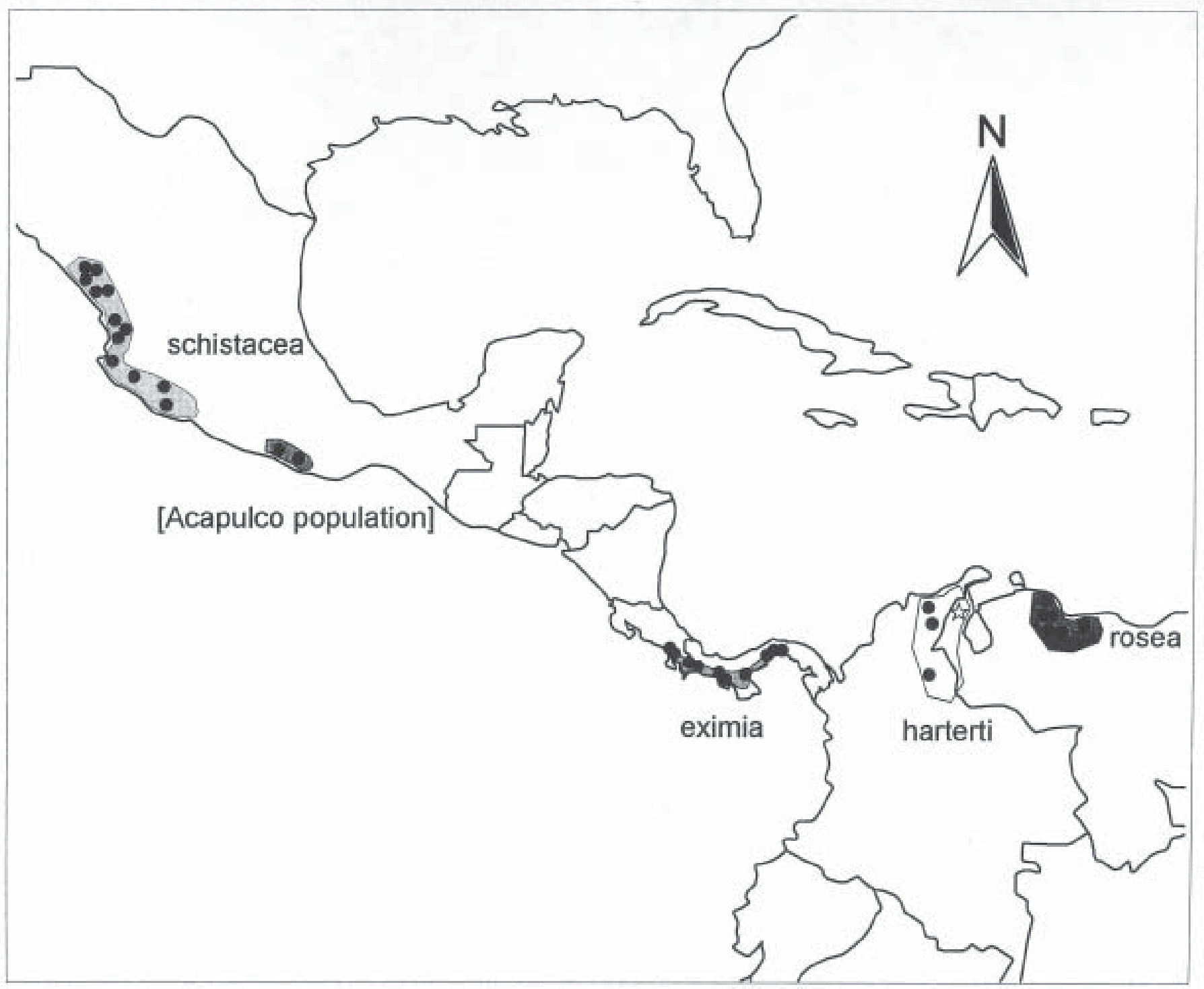

Figure 1. Distribution of populations of Rhodinocichla, showing the geographic units used for statistical analysis. Dots indicate localities of specimens included in this study, and the star indicates the sole individual of the subspecies beebei available for this study. 

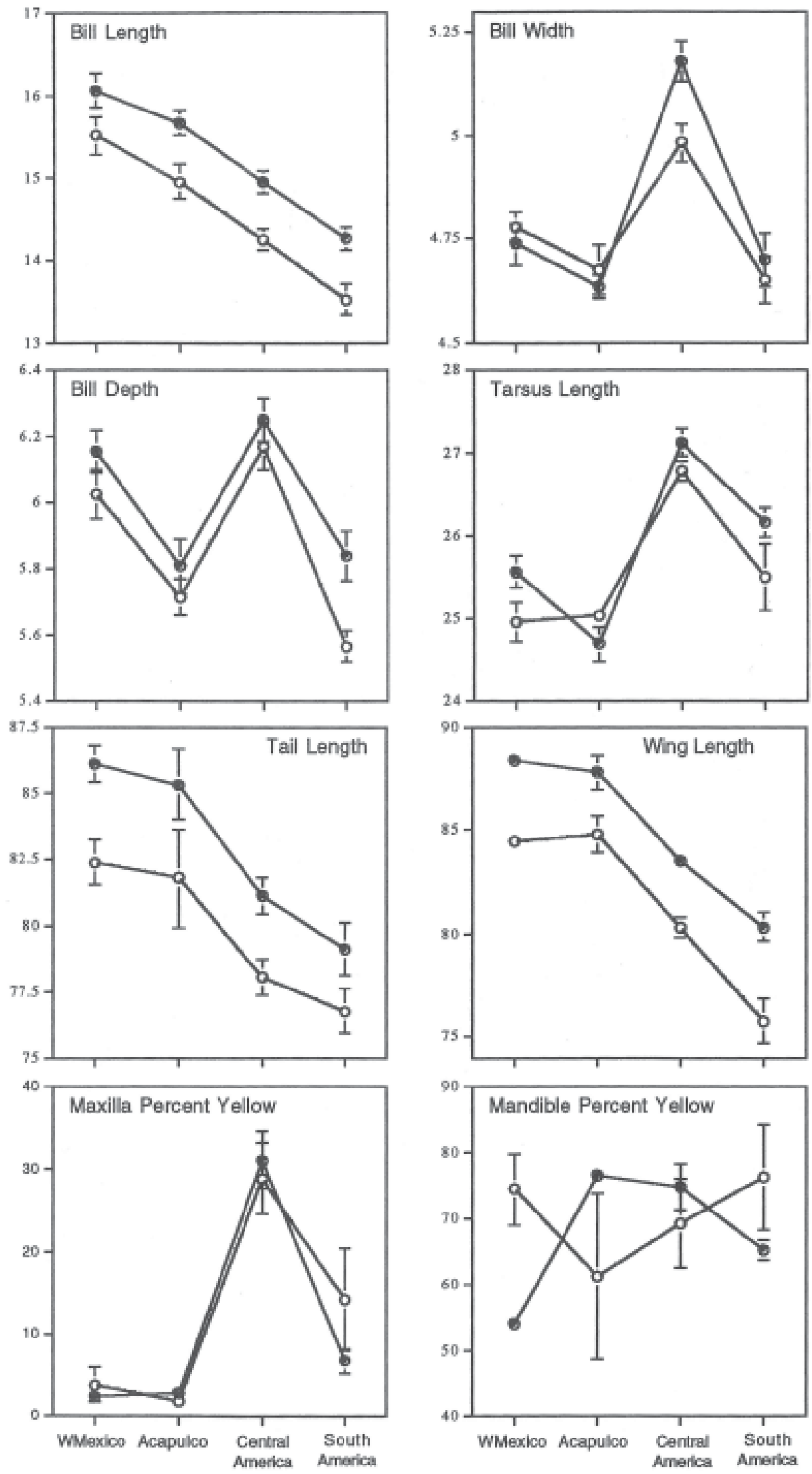

Figure 2. Geographic patterns of variation in six measurements ( $\mathrm{mm}$ ) and two aspects of bill coloration (percent yellow). Shown is the mean + one standard error. 


\begin{tabular}{|c|c|c|c|c|c|c|}
\hline & & $\underline{\text { Males }}$ & & & $\underline{\text { Females }}$ & \\
\hline Character & Back & Breast & Superciliary & Back & Breast & Superciliary \\
\hline $\begin{array}{l}\text { schistacea - western } \\
\text { Mexico }\end{array}$ & Medium gray & $\begin{array}{l}\text { Faded electric } \\
\text { pink }\end{array}$ & Pronounced & Medium gray & $\begin{array}{l}\text { Warm yellow } \\
\text { brown }\end{array}$ & Pronounced \\
\hline schistacea-Acapulco & Medium gray & $\begin{array}{l}\text { Faded electric } \\
\text { pink }\end{array}$ & Pronounced & Medium gray & $\begin{array}{l}\text { Warm yellow } \\
\text { brown }\end{array}$ & Pronounced \\
\hline eximia & Black & Red-pink & Pronounced & Black & $\begin{array}{l}\text { Medium } \\
\text { brown }\end{array}$ & Pronounced \\
\hline harterti & Medium gray & Faded red-pink & $\begin{array}{l}\text { Somewhat } \\
\text { reduced }\end{array}$ & Medium gray & $\begin{array}{l}\text { Warm yellow } \\
\text { brown }\end{array}$ & Prominent \\
\hline beebei & Medium gray & Faded red-pink & Reduced & Medium gray & $\begin{array}{l}\text { Warm yellow } \\
\text { brown }\end{array}$ & $\begin{array}{l}\text { Prominent } \\
\text { (Phelps and } \\
\text { Phelps Jr. 1949) }\end{array}$ \\
\hline rosea & Medium gray & Faded red-pink & Pronounced & Medium gray & Yellow brown & Pronounced \\
\hline
\end{tabular}

Table 1. Summary of plumage characters in males and females of subspecies of Rosy Thrush-tanager populations. 
tests, all $P<0.05$ in both sexes; Figure 2). Mexican populations were strikingly larger in wing, tail, and bill length, but had shorter tarsi, and hence differed from other populations not simply in size and overall dimensions, but in shape as well. Differentiation among other populations was not as striking, consisting of more subtle differences among populations. No geographic patterns of variation (i.e., clinal variation) were detected within the populations tested.

Comparing the two Mexican populations, body dimensions were generally similar. Significant differences were present in both sexes in bill depth (Acapulco populations having shallower bills), and in males in tarsus length (Acapulco populations having shorter tarsi). Although these tests are based on relatively small samples and bill depth is not a particularly precise measurement, they may indicate genetic isolation of the two populations.

We used a cluster analysis of population means for the six measurements to evaluate overall similarity in size and shape of the different populations. In the analyses for both sexes, the two Mexican populations were most similar in morphometric space. Central and South American populations were most similar to each other, and the two clusters were only distantly connected, for an overall pattern of ((Western Mexico, Acapulco), (Costa Rica, South America)). Hence, overall shape features of the Mexican populations separated them in morphological space from the remaining populations.

Striking variation exists among populations in plumage coloration. Males from western Mexico and Acapulco have back and flanks medium gray and breast faded electric pink; males from South American populations are similar, although breast color could be described as faded red-pink. Males in the intervening populations of Costa Rica and Panama, however, are very distinctive, with back and flanks black, and the breast bright red-pink. The superciliary line is marked in Mexican and Central American populations, somewhat less obvious in the populations of northern Venezuela, but obsolete in the intervening populations of Colombia and northwestern Venezuela. Variation in coloration of females parallels that of males, with similar shades of gray and black on back and flanks; the breast and throat were warm yellow brown in individuals from Mexico, Colombia, and northwestern Venezuela, slightly less warm in northern Venezuelan individuals, but much darker and stronger in color in birds from Central America. Therefore, overall plumage variation is parallel in both sexes, and the degree of sexual dichromatism does not vary among populations.

Therefore, geographic variation in Rhodinocichla populations forms two independent "leapfrogs." Graybacked populations in Mexico and South America are separated by the black-backed Central American eximia. The populations harterti and beebei, of Colombia and northwestern Venezuela have reduced superciliary lines, but sepa- rate schistacea and rosea of Mexico and northern Venezuela, which both have that feature well developed. The evolutionary patterns that could produce this sort of geographic variation are obscure, probably involving fixation of novel traits in isolated intermediate populations independent of their neighbors, leaving similar populations separated by distinctive ones (Remsen 1984).

Individual bills ranged from dusky gray-brown to dull yellow in coloration, reminiscent of many corvids, in which juveniles have light-colored bills, which gradually darken with age, and by 1-3 yr of age are completely dark (Peterson 1991a, 1991b). Strangely, though, in Rhodinocichla, specimens in juvenal plumage or molting into a first basic plumage were no more likely to have lightcolored bills than adults (Mann-Whitney $U$-tests, all $P>$ $0.30)$. Also, geographic variation in mandible coloration was not statistically significant (Kruskal-Wallis tests, $P>0.05$ ); both sexes did show significant among-population differences in maxilla coloration $(P<0.05)$. Therefore, although bill color variation observed in Rhodinocichla apparently does not represent ontogenetic variation, geographic differences of unknown significance do exist.

\section{Discussion}

Our analyses illustrate the unpredictable nature of geographic variation in Rhodinocichla. All features examined, including measurements, plumage coloration, sexual size dimorphism, and bill coloration show statistically significant variation among populations. Characteristics of each isolated population seem randomly assorted with regard to other characteristics and populations, and clear geographic trends or predictable combinations do not appear to exist.

Each geographic isolate is distinct, with the possible exception of populations described as beebei, which are close to harterti geographically (about $75 \mathrm{~km}$ ). Given that many harterti have superciliary lines as reduced as the single beebei individual available to us, we initially suspected that this subspecies would prove invalid. Because series sufficient to test this idea were unavailable in the United States, Miguel Lentino of the Sociedad de Conservación "Audubon" and the Colección Ornitológica "Phelps," kindly reviewed series of both subspecies, and concluded that individuals of beebei indeed do have distinctly reduced superciliary lines, and that the characters on which the subspecies was based (Phelps and Phelps 1949) are valid. The distinctiveness of the two Mexican populations rests on differences in mensural characters-detailed populationgenetic studies of their reproductive continuity would be interesting. All remaining populations differed from each other in some respect: for example, although the populations of western Mexico resembled those of northern Venezuela in coloration, they have much larger bills, longer wings and tails, and shorter tarsi. 
An important aspect of any modern assessment of geographic variation is a discussion of species limits. The two species concepts currently used in ornithology-the phylogenetic species concept (PSC) and the biological species concept (BSC) — often yield different taxonomies. In the present case, each of the four major geographic isolates (Mexico, Costa Rica and Panama, Colombia and northwestern Venezuela, and northern Venezuela) is clearly diagnosable, and should be considered a separate species under the PSC. Indeed, from Figure 2, even the Acapulco population appears diagnosable, although plumage differences are lacking. Pending more detailed study of longer series, this population may warrant description as a separate taxon.

The BSC, however, uses as its principal criterion reproductive isolation, which in a disjunctly distributed species such as this is impossible to test directly, so decisions are far more nebulous. However, given the conflicting nature of variation in different character sets (e.g., Mexican populations are most distinctive in terms of size and shape, Central American populations in terms of coloration), detection of limits is difficult. Moreover, given that geographic variation within other Emberizid species is often of the magnitude of the differences observed without apparent reproductive isolation, subdivision of this complex may not be warranted at the present time (Remsen et al. 1991).

A more basic question is that of why disjunct distributions such as the present example exist. Large range disjunctions, coinciding at least in part with those described herein, are known in several other taxa: Ara militaris (northern vs. southern populations), Cyanocorax yncas (northern vs. southern populations), Cyanocorax dickeyi vs. $C$. mystacalis, Cypseloides storeri vs. C. cryptus, Lophornis brachylopha vs. L. delattrei, Thalurania ridgwayi vs. T. colombica, and Zenaida asiatica (northern vs. southern populations). The apparent western Mexico - Guerrero disjunction is mirrored by patterns in the San Blas Jay (Cyanocorax sanblasianus), also for unknown causes. Unlike the better-known disjunctions of many taxa between the isolated montane forests of the Andes, the Guianan Shield, and the mountains of southeastern Brazil, these disjunctions lie in the midst of seemingly continuous and appropriate habitat.

\section{Acknowledgments}

We thank the curators of the collections listed above for the generosity and dedication in providing loans of specimens for this study. We thank J. Dan Webster and Miguel Lentino for open sharing of data and information.

\section{Literature Cited}

EISENMANN, E. 1962. On the systematic position of Rhodinocichla rosea. Auk 79:640-648.
LESSON, R.-P. 1832. Illustrations de zoologie, livre 2. A. Bertrand, Paris.

NAVARRO-SIGÜENZA, A. G., A. T. PETERSON, P. ESCALANTE-PLIEGO, and H. BENITEZ-DÍAZ. 1992. Cypseloides storeri: a new species of swift from Mexico. Wilson Bulletin 104:55 64.

PETERSON, A. T. 1991a. Geographic variation in beak color maturation rates in Gray breasted Jays. Condor 93:448 452.

PETERSON, A. T. 1991b. Sociality and ontogeny of coloration in the blue and black jays (Cyanocorax). Wilson Bulletin 103:5967.

PHELPS, W. H., and W. H. PHELPS, Jr. 1949. Seven new subspecies of birds from Venezuela. Proceedings of the Biological Society of Washington 62:185-196.

REMSEN, J. V. Jr. 1984. High incidence of "leapfrog" pattern of geographic variation in Andean birds: implications for the speciation process. Science 224:171-173.

REMSEN, J. V. Jr., O. ROCHA O., C. G. SCHMITT, and D. C. SCHMITT. 1991. Zoogeography and geographic variation of Platyrinchus mystaceus in Bolivia and Peru, and the circum-Amazonian distribution pattern. Ornithología Neotropical 2:77-83.

SEUTIN, G., and E. BERMINGHAM. 1997. Rhodinocichla rosea is an emberizid (Aves; Passeriformes) based on mitochondrial DNA analyses. Molecular Phylogenetics and Evolution 8:260-274.

SKUTCH, A. F. 1962. On the habits of the Queo, Rhodinocichla rosea. Auk 79:633-639.

WEBSTER, J. D. 1988. Skeletons and the genera of tanagers. Proceedings Indiana Academy of Sciences 98:581593.

Title: Geographic Variation in the Rosy Thrush-tanager (Rhodinocichla rosea) Complex of Mesoamerica (Aves: Passeriformes)

Authors: A. Townsend Peterson, Nathan H. Rice, and Adolfo G. Navarro-Sigüenza

Biota Neotropica, Vol. 4 ( number 2): 2004

http://www.biotaneotropica.org.br/v4n2/pt/ abstract?short-communication+BN02304022004

Date Received: 04/16/2004 - Revised: 06/24/2004

Accepted: 07/01/2004

ISSN 1676-0611 